\title{
Anetoderma through the dermoscope
}

\author{
Subrata Malakar', Samipa Samir Mukherjee ${ }^{2}$
}

${ }^{1}$ Department of Dermatology, Rita Skin Foundation, Kolkata, India, ${ }^{2}$ Department of Dermatology, Cloud nine HospitalBangalore and Rita Skin Foundation, Kolkata, India

Corresponding author: Dr. Samipa Samir Mukherjee, E-mail: drsamipamukherjee@gmail.com

Sir,

Anetoderma is a rarely encountered benign dermatological condition in which the elastic tissue in the dermis is lost, resulting in localized areas of flaccid or herniated saclike skin [1]. Currently, anetoderma is classified as either primary (idiopathic), or secondary anetoderma (which is associated with a variety of skin conditions, penicillamine use, or neonatal prematurity). Lesions appear on the upper arms, trunk, and thighs. This rare disorder occurs mainly in women aged $20-40$ years, but is occasionally reported in younger and older patients of both sexes. In the most usual form, crops of round or oval, pink macules $0.5-1$ centimeter in diameter develop on trunk, thighs and upper arms, less commonly on the neck and face and rarely elsewhere. Elsewhere. The origin may be primary or secondary, primary causes include Schweninger-Buzzi type which has no preceding erythema, and Jadassohn-Pellizari type which is preceded by macular erythema or papular urticaria. Secondary anetoderma occurs at sites of skin diseases such as acne, varicella, xanthoma, discoid lupus erythematosus, granuloma annulare, syphilis [2].

A 32 year old lady presented with asymptomatic lesions over the upper back slowly progressing in number and extent since one year. The family and past history was non contributory. She did not give any history of lesions prior to the occurrence of the current complaints. Dermatological examination revealed multiple skin colored to faintly erythematous macules over the upper back. Few of the lesions were slightly depressed as compared to the normal skin (Fig. 1). Dermoscopy of the lesions shows a background of erythematous hue with partially obliterated pigment network. The skin of the affected area has a transluscent appearance as compared to the surrounding skin (Fig. 2). On examining of another dermoscopic field multiple lesions are noted

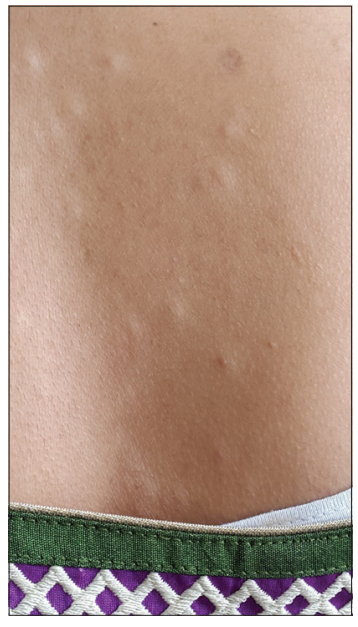

Figure 1: Asymptomatic macular lesions over the back.

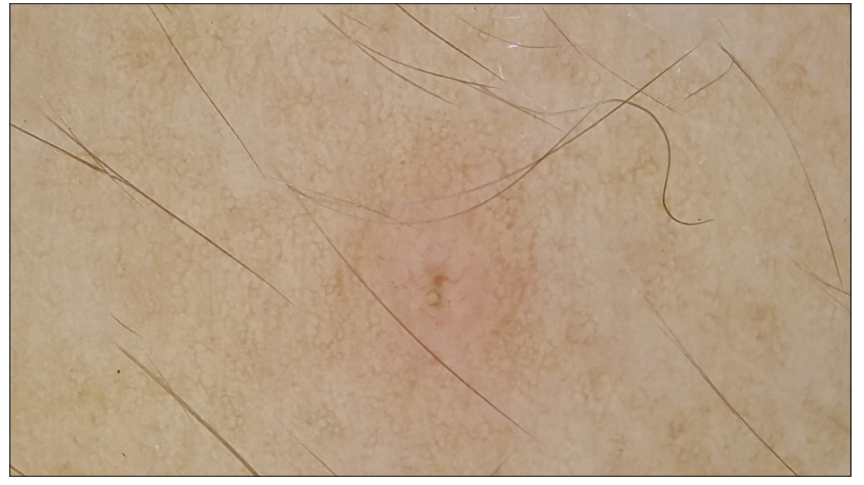

Figure 2: Dermoscopy shows a background of erythematous hue with partially obliterated pigment network. The skin of the affected area has a transluscent appearance as compared to the surrounding skin.

showing erythematous background with multiple linear vessels and transluscent appearance of the skin (Fig. 3).

Venencie et al. [3], in their report suggested that the degradation of elastic fibres in patients with anetoderma is caused by enhanced expression of progelatinases $\mathrm{A}$ and $\mathrm{B}$ and production of the activated form of gelatinase $A$, where the lack of

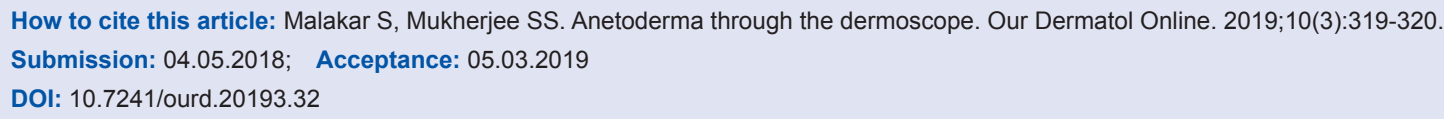






Figure 3: Multiple lesions are noted showing erythematous background with multiple linear vessels and transluscent appearance of the skin. The vasculature becomes visible due to thinning of the skin resulting from degradation of elastin.

control of these enzymes by tissue inhibitors of metalloproteinases results in the development of the anetoderma lesions. The transluscent nature of the skin noted on dermoscopy results from the loss of elastin tissue that is seen on histology in these lesions. The vasculature becomes visible due to thinning of the skin resulting from degradation of elastin. The background erythema results from the underlying inflammation. It may be postulated that the mild inflammation may interfere with the melanocytes in the basal layer leading to partial obliteration of the pigment network.
Dermoscopy may provide an important clinical clue towards the diagnosis of this rare entity by highlighting the transluscent nature of the skin pointing towards the diagnosis. To the best of our knowledge this is the first report of dermatoscopic findings in anetoderma and we believe that dermoscopy may be an important auxiliary tool for the quick and effective diagnosis of this disorder although histology remains the gold standard for diagnosis.

\section{Consent}

The examination of the patient was conducted according to the Declaration of Helsinki principles.

\section{REFERENCES}

1. Rafiei R, Hojat E, Daryakar A, Yusefkhani L, Rafiee B. Anetoderma with positive Darier's sign. Our Dermatol Online. 2017;8:53-5.

2. Kolanuvada P, Sujatha C, Ambika H. Disseminated superficial porokeratosis and anetoderma developing after acute pancreatitis. Our Dermatol Online. 2012;3:228-30.

3. Venencie PY, Bonnefoy A, Gogly B, Groult N, Kut C, Pellat B, et al. Increased expression of gelatinases $\mathrm{A}$ and $\mathrm{B}$ by slin explants from patients with anetoderma. Br J Dermatol. 1997;137:517-25.

Copyright by Subrata Malakar, et al. This is an open-access article distributed under the terms of the Creative Commons Attribution License, which permits unrestricted use, distribution, and reproduction in any medium, provided the original author and source are credited.

Source of Support: Nil, Conflict of Interest: None declared. 